\title{
Female Urethral Injuries Associated with Pelvic Fractures
}

\section{Nerli RB*, Sujata M Jali and Murigendra B. Hiremath}

Department of Urology, KLES Kidney Foundation, KLE University's JN Medical College, KLES Dr Prabhakar Kore Hospital \& MRC Belgaum 590010, India

\begin{abstract}
Introduction: Urethral injuries associated with pelvic fractures are regarded as rare in women and thus discussed infrequently. We reviewed our series of girls/women who presented with urethral injuries.

Materials and Methods: Eleven patients (age range 8-49 years) presenting with urethral injuries and admitted to urological services were reviewed. All had associated injuries, generally more severe than seen in males with urethral injuries.

Results: All the eleven patients had severe injuries. Three of them underwent immediate repair of the urethra, whereas the remaining eight underwent repair 7-15 days later. In the follow-up period three developed stricture, one needing a Mitrofanoff's procedure to self catheterize and the remaining two needing regular dilatation. One patient developed urinary incontinence.
\end{abstract}

Conclusions: Pelvic fractures are associated with urethral injuries, though less common among the females. A more severe injury is needed to damage the female urethra than is necessary in males.

Keywords: Pelvic injury, Urethral injury, Female, Prevalence, Associated injuries

\section{Introduction}

Injury to female urethra due to pelvic fracture is less common than that for similar injuries in males ( $0-6 \%$ vs $10 \%$ in males), likely as the result of greater mobility, relatively protected and shorter length of the urethra in females. Inability to void, urinary incontinence through vagina, haematuria or blood at the introitus in the setting of pelvic trauma should make one suspicious of an associated urethral injury [1]. Most female urethral injuries are longitudinal lacerations in females with less severe mechanisms of injury [2]. Such lacerations can get easily overlooked as catheterization is easily possible in such patients. However Venn et al. [3] and Podesta et al. [4] noted that avulsion/distraction of urethra was more commonly associated with major trauma and severe injuries. Such avulsion injuries are less likely to be overlooked, due to inability to catheterize and higher chance for concomitant vaginal or rectal laceration and blood per vault. We report our experience with female urethral injury associated with pelvic fracture.

\section{Materials and Methods}

Case records of females presenting with traumatic urethral injury as a consequence of a pelvic fracture during the period April 2000 to Dec 2010 were retrospectively reviewed. Age, clinical presentation, associated injuries, initial management, delayed management, complications and outcome were noted.

\section{Results}

During the 10 year period 11 females (age 8-49 yrs) presented with urethral injury in conjunction with pelvic fracture. Ten of these had this injury following road traffic accident, and the remaining one sustained injury following bull-gore injury. Five of these females were below the age of 18 years. All these patients were brought in shock to the causality within 6 hours of injury. All these females had multi system injuries and four of them had periods of unconsciousness due to associated head injury. Genital examination revealed blood at intriotus in 10 of these females (Figure 1). It was not possible to catheterize in six females, as the external urethral meatus was not located due to associated vaginal tear and bleeding. Attempts to catheterize in the remaining five also failed as the catheter was not entering the bladder. Suprapubic catheterization was done in all. Associated injuries included head injury in four, vaginal tear in eight, rectal injury in two, abdominal injury in three, multiple skeletal injuries (Figure 2 and 3) in six and chest injury in one.

Nine of these females had avulsion of the urethra and the remaining two had avulsion with longitudinal tears of the bladder continuing to the proximal urethra (Figure 4). Three of these females underwent exploration for abdominal and rectal injuries. This opportunity was utilized to repair the vaginal tears (Figure 5) as well as the urethral avulsion. The cut edges of the urethra were freshened and approximated over a splinting catheter. The remaining eight underwent exploration 7-15 days later. Management of associated injuries took priority over urethral injuries. In these eight patients also the avulsed urethra was approximated over a splinting catheter.

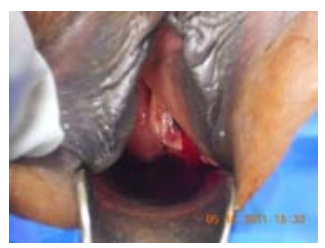

Figure 1: Per Speculum examination showing bony fragment piercing the vagina and avulsing the urethra.

${ }^{*}$ Corresponding author: Dr. Rajendra B. Nerli, Professor \& Head, Department of Urology, KLES Kidney Foundation, KLE University's JN Medical College, KLES Dr Prabhakar Kore Hospital \& MRC Belgaum 590010, India, Tel: 00918312473777 (1394) ; Fax: 0091831 2470732; E-mail: rajendranerli@yahoo.in, director@kleskf.org

Received March 12, 2012; Accepted April 02, 2012; Published April 05, 2012

Citation: Nerli RB, Jali SM, Hiremath MB (2012) Female Urethral Injuries Associated with Pelvic Fractures. J Trauma Treat 1:126. doi:10.4172/2167 1222.1000126

Copyright: (C) 2012 Nerli RB, et al. This is an open-access article distributed under the terms of the Creative Commons Attribution License, which permits unrestricted use, distribution, and reproduction in any medium, provided the original author and source are credited. 


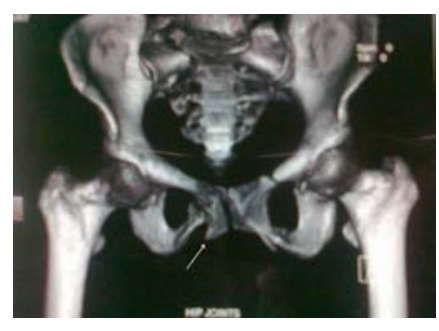

Figure 2: CT reconstruction of fracture pelvis in 49 year old female presenting with urethral injury. Sharp bony fragment which was piercing through into vagina and avulsing the urethra (Arrow).

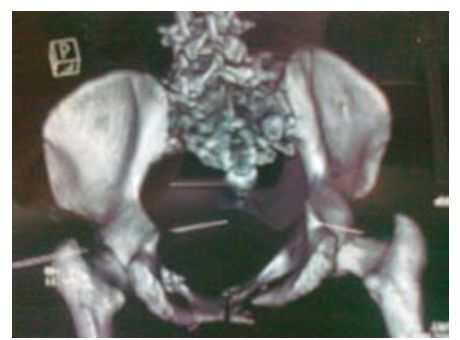

Figure 3: CT reconstruction of 36 year old female presenting with avulsion of the urethra with multiple pelvic fractures.

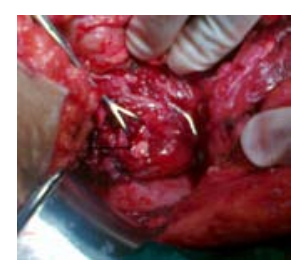

Figure 4: Avulsed bladder and urethra in patient 2.

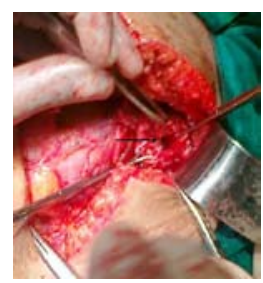

Figure 5: Transpubic exploration of urethra in patient 1. Rent in the vagina (arrow).

Most of the patients took prolonged time to recover because of multiple injuries (Figure 6 and 7). In long term follow-up one patient with injury to bladder and bladder neck avulsion developed urinary incontinence. None of the patients developed fecal incontinence. Two other patients had stricture at the site of injury/repair, and both these women are on regular urethral dilatation program. On young female who was 11 years old at the time of injury had persistent stricture, which completely closed. This patient underwent a Mitrofanoff's procedure for self catheterization.

\section{Discussion}

Urethral injuries following a pelvic fracture in females are rare [5], so rare that many a times these go un-noticed/ignored or even overtly considered non-existent [6]. In most instances urethral injuries have been reported in girls [7] rather than adults [8] suggesting that adults are either less vulnerable [7] or tend to die more commonly from associated injuries [2]. Perry and Husmann's report [2] on urethral injury in 1992 which involved 6 women is still referred to date. Five of these women had a variable longitudinal tear from the bladder down through the bladder neck and into the urethra. Only one woman had a transverse tear transecting the urethra in isolation. This report is distinct from the previous reports which describe disruption (transaction or avulsion) injuries, generally at the bladder neck [3].

The incidence of pelvic fracture injuries in females remains unclear. Overall, pelvic fractures are common in females than in males, with a ratio of 1.5:1 [9]. In younger population, males predominate, whereas in the age group of 50 and above, females predominate. Orkin [8] reported an incidence of $6 \%$ of urethral injuries associated with pelvic fractures, whereas a $4.6 \%$ incidence in 130 pelvic fractures was reported by Perry and Husmann [2]. Blandy [10] described an interesting series of 157 women with pelvic fractures and in whom five had a ruptured urethra, one had a rectal injury along with vaginal and urethral injury, and four had bladder and urethral injury.

These series confirm the association of urethral injuries with pelvic fracture in women, although less commonly than in males. This lower incidence of urethral injury in women could probably be because the urethra in the female is relatively well protected, flexibility provided by the vagina and because of the greater inherent elasticity of the adult female urethra [7]. This probably also explains the reason as to why urethral injury is more common in girls as compared to adult women. Longitudinal lacerations are less severe/serious injuries as compared to avulsion/distraction, as these latter injuries are generally associated with far more severe associated injuries [3]. Longitudinal lacerations are more commonly associated with an anteroposterior compression (open book) injury, whereas an avulsion/distraction injury is more commonly associated with a lateral compression injury [3]. Damage to the nerves may occur alone or in conjunction with an otherwise uncomplicated urethral injury and present subsequently as sphincter weakness incontinence [3]. Blandy [10] commented that four patients who had no obvious urethral injury at the time became incontinent

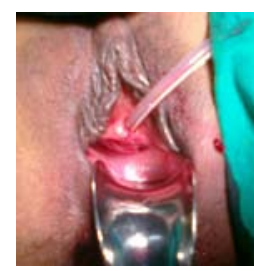

Figure 6: Post operative result. Bony fragment removed, urethra and vagina repaired with catheter exiting the External Meatus. (Note normalization of position of External Meatus).

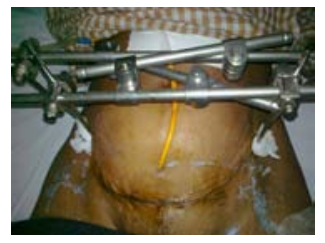

Figure 7: Post operative photograph with external fixators in situ. 
after fracturing their pelvis. Such injuries and simple longitudinal tears of the bladder and urethra are more of continence than a structural problem. It is important to recognize these injuries and a vaginal examination should be mandatory after a pelvic fracture in females, as urethral and other injuries are regularly overlooked, sometimes with serious consequences.

It is difficult to suggest recommendations on the treatment of these injuries as these injuries are less common, and these suggestions can be only based on a wide diversity of case reports and small series. The less severely injured patient most probably has an anterior laceration and does not need any repair of the same initially. A suprapubic catheterization to provide drainage and a ureteric catheter to provide splinting of the urethra is all that is necessary until the injury has healed. Any subsequent incontinence could then be treated. Avulsion injuries do not get overlooked because of the severity of the trauma and invariably be associated with vaginal/rectal injury and the genital bleeding will draw attention to these injuries. It is not possible to catheterize these patients per-urethra at presentation. The vaginal injuries need to be repaired, if only to control the bleeding. If the rectum is injured, it needs to be repaired with a covering colostomy. The urethra can be repaired by bringing the ends together around a splinting catheter.

\section{Conclusions}

Urethral injuries in females though uncommon are associated with severe trauma and multiple skeletal and organ injuries. Vaginal/genital examination is a must so that these injuries do not get overlooked. Continuity of the urethra can be maintained by approximating the two ends over a splinting catheter.

\section{References}

1. Anast J, Brandes SB and Klutke C (2008) Female urethral reconstruction. Urethral Reconstructive Surgery 303-313.

2. Perry MO, Husmann DA (1992) Urethral injuries in female subjects following pelvic fractures. J Urol 147: 139-143.

3. Venn SN, Greenwell TJ, Mundy AR (1999) Pelvic fracture injuries of the female urethra. BJU Int 83: 626-630.

4. Podesta ML, Jordan GH (2001) Pelvic fracture urethral injuries in girls. J Uro 165: $1660-1665$.

5. Carter CT, Schafer N (1993) Incidence of urethral disruption in females with traumatic pelvic fractures. Am J Emerg Med 11: 218-220.

6. Kaiser TF, Farrow FC (1965) Injury of the bladder and prostatomembranous urethra associated with fracture of the bony pelvis. Surg Gynecol Obstet 120 99-112.

7. Patil U, Nesbitt R, Meyer R (1982) Genitourinary tract injuries due to fracture of the pelvis in females: sequelae and their management. Br J Urol 54: 32-38.

8. Orkin LA (1983) Trauma to the bladder, ureter and kidney. In Sciarra JJ, Gynecology and Obstetrics. Harper Row Publishers, Philadelphia.

9. Luthje P, Nurmi I, Kataja M, Helliovaara M, Santavirta S (1995) Incidence of pelvic fractures in Finland in 1988. Acta Orthop Scand 66: 245-248.

10. Blandy JP (1980) Urethral stricture. Postgrad Med J 56: 383-481. 